\title{
Performance of Ultrasonic Testing for Different Steel Sheets which are joined by Spot Welding
}

\author{
Chilla Veera Venkata Satyanarayana, Uppada Komali
}

\author{
Assistant Professor, Department of Mechanical Engineering, \\ Bhimavaram Institute of Engineering \& Technology, Goraganamudi, Andhra Pradesh, India
}

\begin{abstract}
How to cite this paper: Chilla Veera Venkata Satyanarayana | Uppada Komali "Performance of Ultrasonic Testing for Different Steel Sheets which are joined by Spot Welding" Published in International Journal of Trend in Scientific Research and Development (ijtsrd), ISSN: 24566470, Volume-3 I Issue-4, June 2019, pp.67-69, URL: https://www.ijtsrd.c om/papers/ijtsrd23 598.pdf

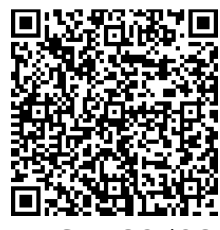
IITSRD23598
\end{abstract}

Copyright (C) 2019 by author(s) and International Journal of Trend in Scientific Research and Development Journal. This is an Open Access article distributed under the terms of the Creative Commons

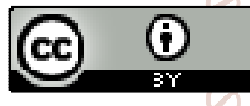
Attribution License (CC BY 4.0) (http://creativecommons.org/licenses/ by $/ 4.0$ )

\section{ABSTRACT}

The main purpose of this paper is to examine the applicability of spot welded dissimilar steel sheets to ultrasonic testing, because resistance spot welding of the steel sheets is widely used in the car bodies and transport fields and ultrasonic testing is a good way to evaluate the fatigue life of the spot welds. Methodology of this paper is that two different steel sheets (AISI 304 type austenitic stainless steel sheet and Galvanized steel sheet) were welded to each other by using resistance spot welding. Some pre-welding tests were made to obtain suitable and optimum weld nugget diameter; and the welding current vs. nugget diameter curve were obtained. By using this curve and keeping constant welding parameters such as current, electrode pressure, weld time, etch. Fully identical four spot welded specimens having $5 \mathrm{~mm}( \pm 0.16)$ nugget diameter were obtained. The specimens and nugget diameters were tested by using a special ultrasonic test apparatus which is designed for spot welded joints. Findings are that after the first ultrasonic tests, the four identical spot welded sheets which have AISI 304 - Galvanized steel sheet combination were subjected to the fatigue test in four different numbers of cycles. There is no any rupture or fracture in spot welded joints after fatigue tests. The spot welded specimens subjected to fatigue test were tested in ultrasonic test apparatus to observe the variation in the weld nugget and joint. The ultrasonic test results before fatigue and after fatigue were compared with each other; and the decreasing of the weld nugget diameter were observed while increasing the number of cycles. The results were shown in figures and discussed. Spot welding of different steel sheets forms different microstructures which respond different values to ultrasonic testing. Evaluation of these responses are quiet difficult. Only a few spot welds can be evaluated among approximately 5 thousands of spot welds on a car body. Only selected spot welds can be ultrasonically tested. Resistance spot welding of AISI 304 and galvanized steel forms austenitic, martensitic and ferritic microstrucutre in the same weld region. Ultrasonic testing of austenitic microstructures is different than the other microstructures. In this study the response of different microstructures to ultrasonic waves are investigated.

Keywords: Ultrasonic testing non-destructive; Resistance spot welding; Different austenitic steels

\section{INTRODUCTIN:}

The corrosion resistance of the steel sheets is very important in car bodies and thus galvanized steel and austenitic stainless steel sheets take the place of the uncoated steel sheets in automotive industries. One of the major concerns in the spot welded joints is fatigue, because these joints are exposed to variable loads in the automobile structures. The fatigue crack begins at the interior surface of welded sheets in the heat affected zone. It is very important to know weld nugget formation of the spot welded member after the fatigue and hence determine the serviceability of the spot welds by ultrasonic testing before rupture. Ultrasonic testing of austenitic structures are different the other types of structures.

The specimens and nugget diameters were tested by using a special ultrasonic test apparatus which is designed for spot welded joints. After the first ultrasonic tests, the four identical spot welded sheets which have AISI 304 Galvanized steel sheet combination were subjected to the fatigue test in four different numbers of cycles. There is no any rupture or fracture in spot welded joints after fatigue tests. The spot welded specimens subjected to fatigue test were tested in ultrasonic test apparatus to observe the variation in the weld nugget and joint.

\section{WELDING PROCESS}

In this work, commercial AISI 304 type stainless steel sheet and galvanized steel sheet were used. The sheet materials were joined as lap joints. The thicknesses of the galvanized and stainless steel sheets are $0.76 \mathrm{~mm}$. and $1.0 \mathrm{~mm}$, respectively. Four identical spot welded specimens were obtained with galvanized steel - austenitic stainless steel 
sheet combination and $4 \mathrm{~mm}$ nugget diameter. Below figure, the photograph of the macro section of the weld nugget is given.

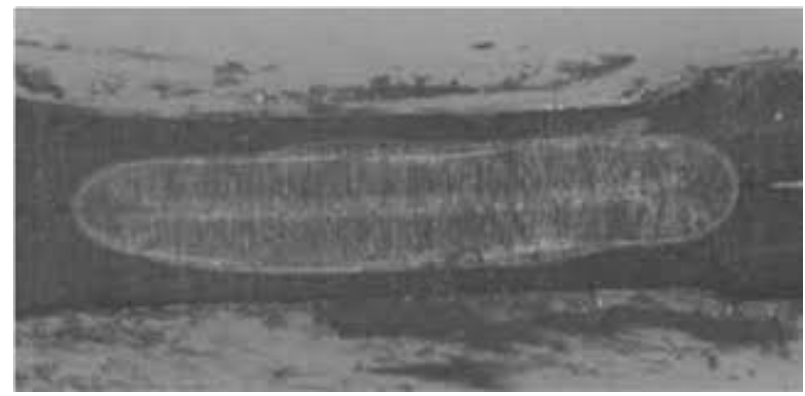

The weld joint has an austenite + martensite + ferrite micro structure. These structures have fully different properties and grain sizes from those of base metals.

\section{FATIGUE TESTS}

The fatigue testing was performed in laboratory conditions. All tests were performed using a sinusoidal waveform operating at $10 \mathrm{~Hz}$. During the fatigue experiments, load and specimen displacements were recorded and monitored by the test control system. Each four spot welded specimens were exposed to fatigue test with $25000,50000,80000$ and 110000 number of cycles respectively.

\section{ULTRASONIC TESTS}

Ultrasonic tests were performed before and after fatigue. Before fatigue tests operation, spot welded specimens are inspected by an ultrasonic test apparatus which has special spot welding probes with different diameters. The results before fatigue showed that four spot welded specimens have suitable nugget diameter, and the obtained weld joints are valid for operation. Below shows the used ultrasonic test apparatus, special spot weld probes and ultrasonic testing.
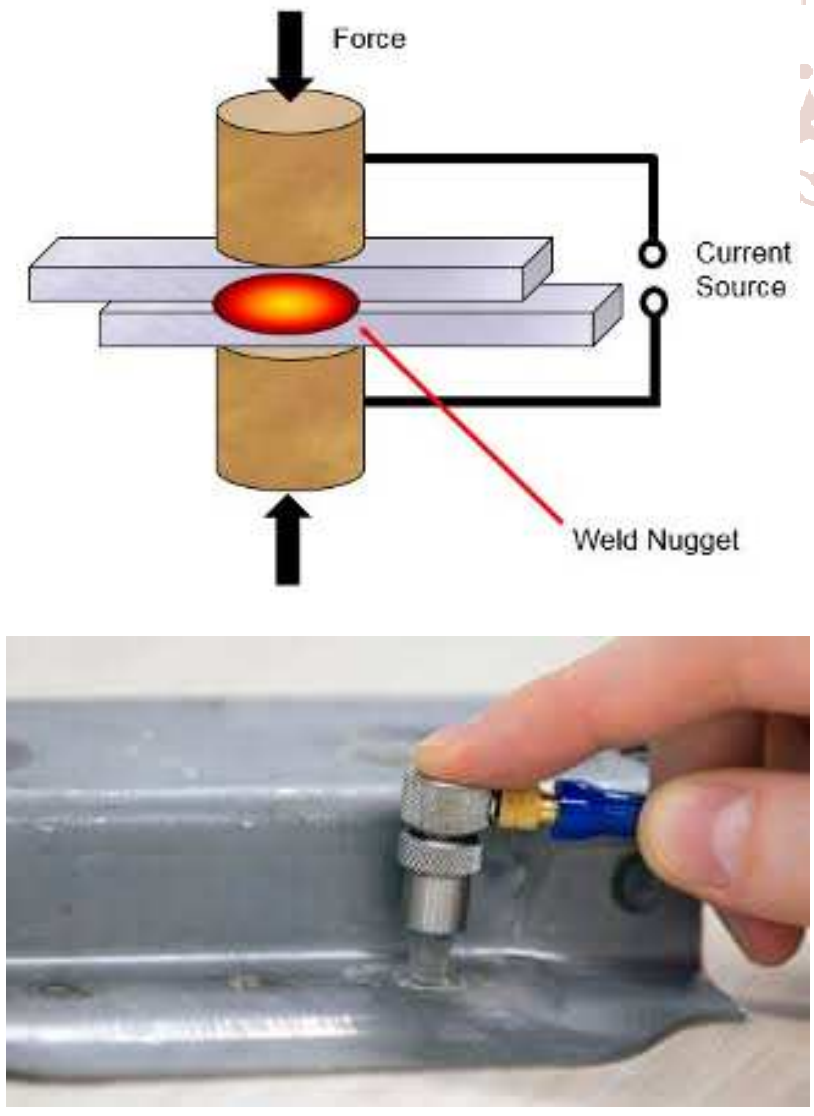

During the fatigue test, the load range and load frequency were kept constant. The specimens exposed to the fatigue test were investigated and it was shown that there was no major damage and rupture on the joints between the steel sheets. After the fatigue test, to observe the decrease of the nugget diameter, the ultrasonic tests were repeated. The ultrasonic test results before and after the fatigue was monitored and compared with each other.

\section{ULTRASONIC TEST RESULTS}

In this step of the study, the results taken by ultrasonic test apparatus were investigated and discussed. Below figure shows the ultrasonic test results of the fatigue specimen exposed to 25000 cycle's fatigue. During the welding operation a deformation is formed around the weld nugget of $0.1 \mathrm{~mm}$.
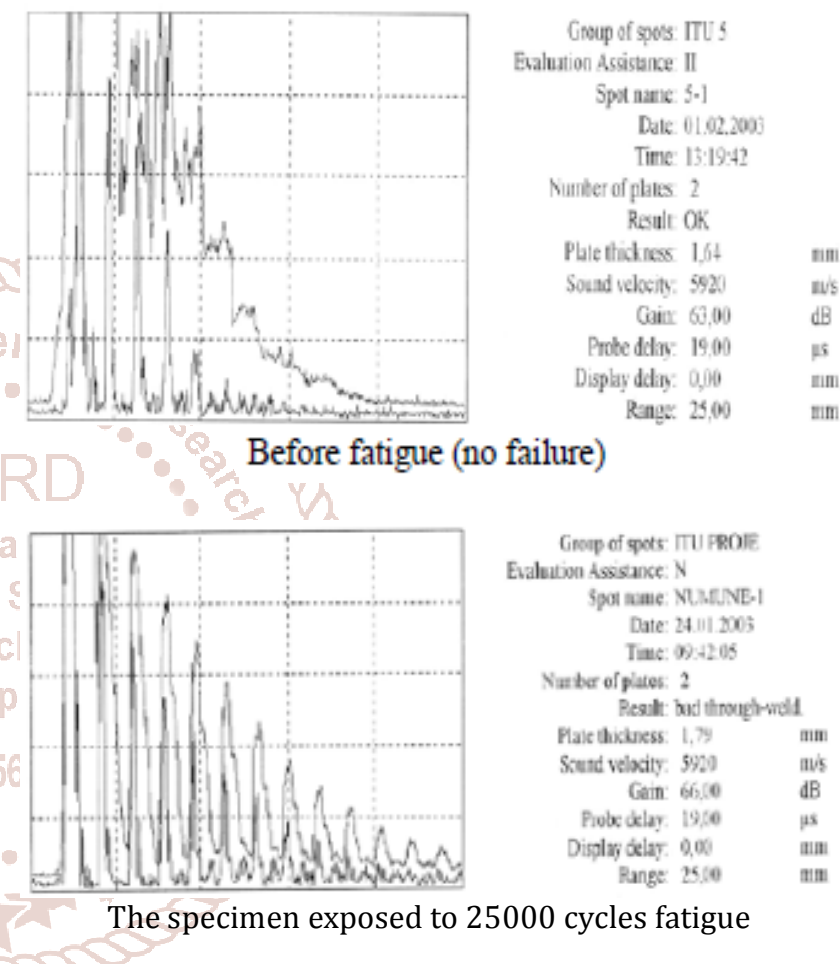

Below figure, the ultrasonic test results of the fatigue specimen exposed to 50000 cycles fatigue is shown.

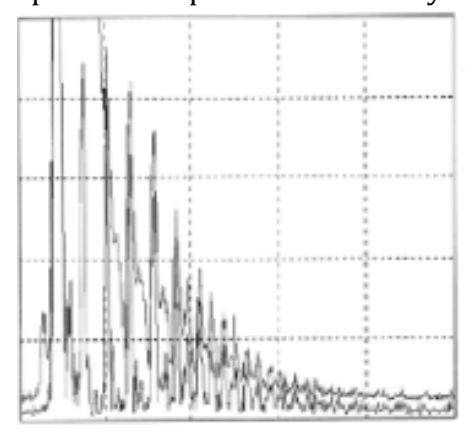

$$
\begin{aligned}
& \text { Group ef spat: ITU PROE } \\
& \text { Evaluxion Asistanoc [] } \\
& \text { Sxt name NIUIJE-? } \\
& \text { Daxe 2461.2000 } \\
& \text { Tine } 095056 \\
& \text { Nuter ef plass } 2 \\
& \text { Resalt snall nugget } \\
& \text { Pure tiskness } 1.35 \\
& \text { Sound ralocity 54b? } \\
& \text { Gain } 74(1) \\
& \text { Prode delas. 1964 } \\
& \text { Diglag delay. 0,0 } \\
& \text { Pang: } 2510
\end{aligned}
$$

The specimen exposed to 50000 cycles fatigue

In this spot welded specimen, the weld nugget diameter after fatigue is $35 \%$ less than the original nugget diameter. Total thickness of the weld zone decreases into $1.35 \mathrm{~mm}$. After the 50000 cycles fatigue, both the cold weld zone around the nugget is deformed and a crack initiation is formed around the weld nugget. Also, decreasing the weld nugget diameter shows the same results. The test results are given as small nugget. 
Below figure shows the ultrasonic test results of the fatigue specimen exposed to 800000 cycles fatigue.
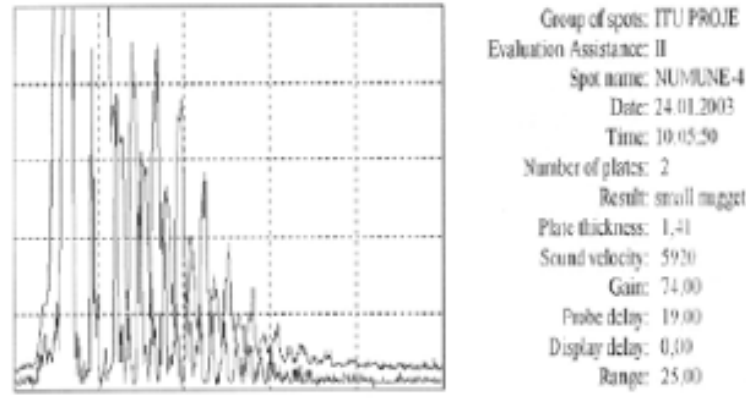

The specimen exposed to 800000 cycles fatigue

Below figure, the ultrasonic test results of the fatigue specimen exposed to 1100000 cycles fatigue is shown.
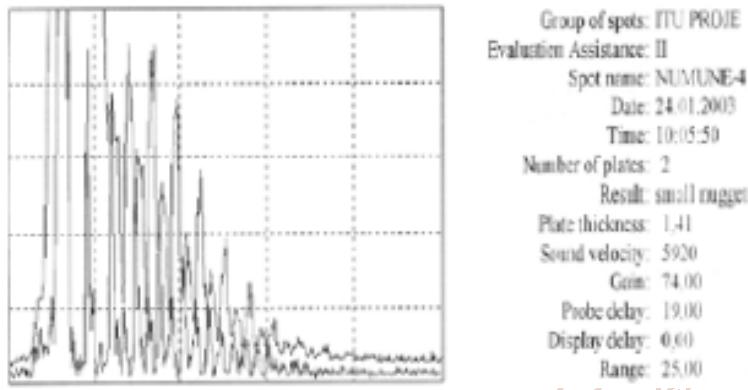

The specimen exposed to 1100000 cycles fatigue

In this 110000 cycle's specimen, the nugget diameter decreases into approximately $1 \mathrm{~mm}$. The test result is given again as small nugget.

The ultrasonic test results show that while the number of fatigue cycle is increased, the weld nugget diameter decreases; but this decreasing is not linear. Below figure shows the effect of the number of the fatigue cycle on the nugget diameter.

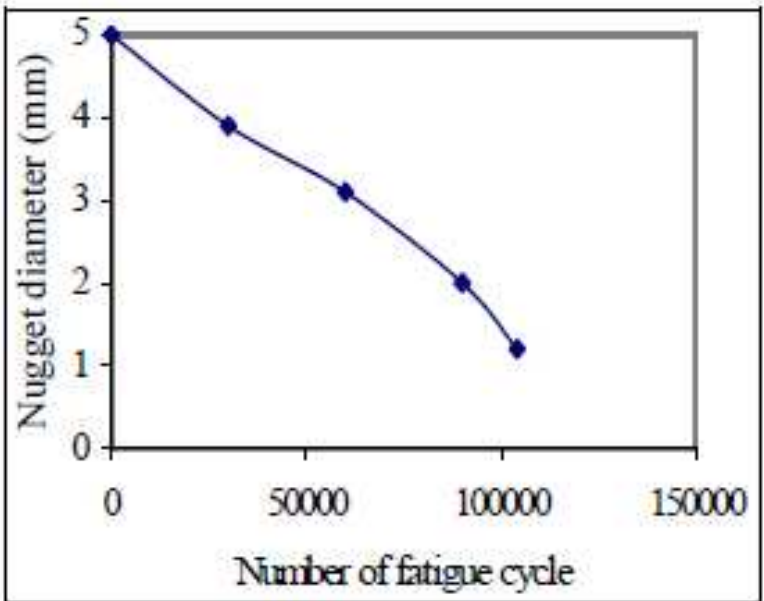

The effect of the number of the fatigue cycle on the nugget diameter
As seen clearly from above figure, while the number of fatigue cycle is increased, the nugget diameter decreases rapidly. It can be said that, the crack growth rate during the fatigue is not constant and it increases while increasing the number of fatigue cycle.

\section{CONCLUSIONS}

In this study, two different steel sheets (AISI 304 type austenitic stainless steel sheet and galvanized steel sheet) were welded to each other by using resistance spot weld. The specimens and nugget diameters were tested by using a special ultrasonic test apparatus specially designed for spot welded joints. After the first ultrasonic tests, the four identical spot welded sheets which have AISI 304 Galvanized steel sheet combination were subjected to the fatigue test up to $25 \%$ stiffness drop. There is no any rupture or fracture in spot welded joints after fatigue tests. The spot welded specimens subjected to fatigue test were tested in ultrasonic test apparatus to observe the variation in the weld nugget and joint.

While the number of fatigue cycles is increased, weld nugget diameter decreases rapidly, and a crack occurs in the weld nugget according to loading mode. In high number of fatigue cycles, the results of the ultrasonic test apparatus are"small nugget". This results show that while the number of the fatigue cycle is increased especially high levels, the weld nugget is not between the valid tolerances, and the crack growth rate increases rapidly. According to the results of the ultrasonic tests, the diameters of the weld nuggets are decreased from $5 \mathrm{~mm}$ to $1 \mathrm{~mm}$ during the fatigue tests. Because the thickness of the materials at the weld zone is quiet small, the ultrasonic test did not show any difference for the different microstructures which are austenite, martensite and ferrite at the weld zone. This shows that ultrasonic tests can be applied to the spot welded joints of different steel sheets.

\section{REFERENCES}

[1] David N. Collins and W. Alcheikh, Ultrasonic nondestructive evaluation of the matrix structure and the graphite shape in cast iron Journal of Materials Processing Technology, Volume 55, Issue 2, 15 November, Pages 85-90, 1995.

[2] H. Yoneyama, S. Shibata and M. Kishigami, Ultrasonic testing of austenitic stainless steel welds False indications and the cause of their occurrence NDT International, Volume 11, Issue 1, February 1978.

[3] N. R. Joshi, Exploration of heterogeneous duplex grain structure in type 304 austenitic stainless steel using ultrasonic spectroscopy Ultrasonics, Volume 17, Issue 5, September 1979, Pages 205 208, 1979.

[4] G. P. Singh and R. C. Manning' Discrimination of ultrasonic indications from austenitic stainless-steel pipe welds NDT International, Volume 16, Issue 6, December 1983, Pages 325-.329 